\title{
Evaluation of multiple satellite evaporation products in two dryland regions using GRACE
}

\author{
O. Lopez, M. F. McCabe and R. Houborg \\ King Abdullah University of Science and Technology, Thuwal 23955-6900, Saudi Arabia \\ Email: oliver.lopez@kaust.edu.sa
}

\begin{abstract}
Remote sensing has become a valuable tool for monitoring the water cycle variables in areas that lack the availability of ground-based measurements. Integrating multiple remote sensing-based estimates of evaporation, precipitation, and the terrestrial water storage changes with local measurements of streamflow into a consistent estimate of the regional water budget is a challenge, due to the scale mismatch among the retrieved variables. Evapotranspiration, including soil evaporation, interception losses and canopy transpiration, has received special focus in a number of recent studies that aim to provide global or regional estimates of evaporation at regular time intervals using a variety of remote sensing input. In arid and semi-arid regions, modeling of evaporation is particularly challenging due to the relatively high role of the soil evaporation component in these regions and the variable nature of rainfall events that drive the evaporation process. In this study, we explore the hydrological consistency of remote sensing products in terms of water budget closure and the correlation among spatial patterns of precipitation $(\mathrm{P})$, evaporation $(\mathrm{E})$ and terrestrial water storage, using P-E as a surrogate of water storage changes, with special attention to the evaporation component. The analysis is undertaken within two dryland regions that have presented recent significant changes in climatology (Murray-Darling Basin in Australia) and water storage (the Saq aquifer in northern Saudi Arabia). Water storage changes were derived from the Gravity Recovery and Climate Experiment (GRACE) spherical harmonic (SH) coefficients. Six remote sensing-based evaporation estimates were subtracted from the Global Precipitation Climatology Project (GPCP)-based precipitation estimates and were compared with GRACE-derived water storage changes. Our results suggest that it is not possible to close the water balance by using satellite data alone, even when adopting a spherical harmonic filtering approach.
\end{abstract}

Keywords: Evaporation, GRACE, dryland, spherical harmonics 


\section{INTRODUCTION}

Monitoring water fluxes over large regions has become increasingly accessible with the availability of satellitebased data covering hydrological variables such as evaporation (Mueller et al., 2013), soil moisture (McCabe et al. 2005), precipitation (Kummerow et al., 2000) and even vegetation response (Liu et al., 2011). To develop these products, data from different satellites has to be merged to effectively cover large regions for precipitation estimation, and/or combined in a conceptual model of evaporation (Ershadi et al., 2014). A further step for validating the combined capability of these independent products to represent land surface processes is to verify their water balance closure (Pan et al. 2012) or hydrological consistency (McCabe et al. 2008). An important goal for remote sensing as a tool for monitoring the water cycle should be to be able to close the water budget of any region in the world, regardless of climate zone or dominant biome type. Currently, there is still some way towards achieving this from remote sensing data alone (Sheffield et al., 2009), but dryland regions with ephemeral or non-existent streamflow could be used as simpler test sites by eliminating this variable from the water budget (Wang et al. 2012):

$$
\Delta S=P-E-Q
$$

Evaporation, which includes the evaporation from soil and transpiration from plants, has been an active area of research recently thanks to the LandFlux (McCabe et al., 2015) and WACMOS-ET (Miralles et al., 2015) projects, as well as the development of the several remote sensing algorithms and products for regional and global scale analysis (Mueller et al. 2013). Some of these products include: the MODIS (MOD16) PenmanMonteith based model of Mu et al.(2011), the Global Land Surface Evaporation: the Amsterdam Methodology (GLEAM) of Miralles et al. (2011), and the Atmosphere Land Exchange Inverse (ALEXI) by Anderson et al. (2011). Jimenez et al. (2011) and Mueller et al. (2011) compared global estimates of evaporation from remote sensing products, land surface models (LSM) and climate reanalyses and found that some of the absolute differences between the satellite products were attributed to different forcing data sets, an aspect that has recently been examined as part of a coordinated tower based analysis (Ershadi et al. 2014).

On the left hand side of (11), the change in water storage includes changes in groundwater, soil moisture, surface water, biomass and snow. Reconciling these components from remote sensing data alone would be impossible due to the lack of a satellite-based groundwater observation. The Gravity Recovery and Climate Experiment (GRACE) (Tapley et al. 2004) however, has allowed to recover vertically-integrated water storage anomalies since its launch in 2002. GRACE resolution is limited to about a few hundred kilometers and monthly values, in contrast to higher resolutions in precipitation, soil moisture, vegetation and evaporation products.

Due to the low resolution constraint of GRACE, the integration of remote sensing products has been tested at large river water basins. For example, Sheffield et al. (2009) evaluated the potential retrieval of streamflow of the Mississippi River basin as a residual of the water budget using GRACE and satellite-based evaporation and precipitation. Sahoo et al. (2011) followed with a similar study over ten globally distributed river basins. Both studies concluded that with remote sensing alone it is not yet possible to achieve water budget closure. There have however, been efforts to downscale GRACE data by using data assimilation techniques, e.g. Houborg et al. (2012). Data assimilation techniques have also been used to constrain the water budget of major global river basins by using multiple sources of data including land surface models, remote sensing, in situ data, and climate reanalysis (Pan et al. 2012).

Here we explore the hydrological consistency of satellite-based products of precipitation, evaporation and water storage across two dryland regions: the Saq aquifer in Saudi Arabia, and the Murray-Darling basin in Australia. The study extends the analysis of Sheffield et al. (2009) and Sahoo et al. (2011) by exploring the degree-correlations between GRACE spherical harmonic ( $\mathrm{SH}$ ) coefficients and the residual of precipitation and evaporation. Since different degrees correspond to different length scales (higher degrees correspond to smaller scales), the study explores the hydrological consistency in terms of the water budget at different scales.

\section{GRACE DEGREE-CORRELATION APPROACH FOR PRODUCT EVALUATION}

GRACE official products are provided as a set of spherical harmonic (SH) coefficients describing the gravity field with water storage obtained after applying a number of post-processing steps to these coefficients. For example, random errors present in the higher degree coefficients are removed by using a smoothing (or Gaussian) filter (Swenson and Wahr. 2006). Systematic errors in the coefficients appear as meridionally oriented stripes that obscure the true hydrologic signal. Swenson and Wahr (2006) developed a de-striping filter to 
remove these correlated errors. However, a side effect of this filter is that the true signal is modified and a last step in the process is scaling the GRACE signal to account for this effect. The scaling factor can be obtained by applying the same filters to the output of a land surface model, as explained by Landerer and Swenson (2012). Long et al. (2015) recently explored the impact that the choice of LSM or scaling technique may have on the water storage anomalies and found that arid and semiarid basins, as well as areas with intensive irrigation, are the most sensitive to the choice of LSM. An alternative to scaling that has received little attention when using GRACE data along with other data sets (e.g. precipitation and evaporation) is to convert these data to spherical harmonics and to apply the GRACE filters to these coefficients directly. Swenson (2010) used this approach when comparing two global precipitation products at high latitudes using GRACE and a water balance approach. One advantage of this method is that (1) can be explored at different length scales by evaluating the degree-correlation:

$$
r_{l}=\frac{1}{\sigma_{l}^{(A)} \sigma_{l}^{(B)}} \sum_{m=0}^{l}\left(C_{l m}^{(A)} C_{l m}^{(B)}+S_{l m}^{(A)} S_{l m}^{(B)}\right)
$$

where $C_{l m}$ and $S_{l m}$ are the spherical harmonic coefficients of degree $l$ and order $m$, and $\sigma_{l}^{2}$ is the degree variance which is the sum of squared coefficients corresponding to a degree $l$. Tapley et al. (2004) used this measure to evaluate the performance of GRACE compared to the Global Land Data Assimilation System (GLDAS), and showed that they are relatively well correlated at large spatial scales but are completely uncorrelated for length scales of around 500-650km (degrees 30 and above).

In this study, we first accumulated the daily evaporation and precipitation estimates to monthly values. Next, we converted these monthly gridded data sets to spherical harmonic coefficients using the algorithm described in Wang et al. (2006), which allows for the fast computation of spherical harmonics from a non-smooth gridded data set. The data was masked to include only the pixels within the study region (e.g. the aquifer or basin). GRACE water storage anomalies were obtained by subtracting the mean of the study period (2003-2014), with water storage change computed as:

$$
\Delta S=\frac{W S A(t+1)-W S A(t-1)}{2}
$$

where WSA is the water storage anomaly and $t$ corresponds to any given month. GRACE coefficients are regionally averaged by multiplying the global coefficients with the SH coefficients describing the study region. The latter is obtained by the same method used to convert the satellite products into spherical harmonics.

\section{STUDY SITES}

In order to test the degree correlation between water storage changes observed by GRACE satellites and remotely sensed precipitation and evaporation, an ideal study site should not contain large active streams so that the third term in (1) can be neglected. The Saq Aquifer in Saudi Arabia, is a major source of groundwater that contains non-renewable water that is being used for agricultural development in the region. The subsurface area of the aquifer is large enough $\left(160,000 \mathrm{~km}^{2}\right)$ for GRACE data to be used significantly and is located in an arid to semi-arid environment (El Kenawy and McCabe, 2015).

To compare the results of an ideal site to one in which runoff is not negligible, but still similarly placed in terms of a predominantly semi-arid climate zone (Evans and McCabe, 2010), we used the Murray-Darling Basin in Australia to further explore the possibility of hydrological consistency between GRACE and satellite-based products using degree-correlation, although ignoring the runoff term. We assume that the spatial distribution of water storage variations over the whole basin is not affected significantly by runoff.

\section{RESULTS}

\subsection{GRACE DEGREE CORRELATION}

The following section presents a set of selected degree correlation analyses comparing GRACE water storage change coefficients corresponding to the same month on different years, as well as different months during the same year. This was done in order to get a sense of the range of degree correlations that could be achieved if similar spatial patterns are to be found when comparing both sides of (1). In this section, we used the coefficients describing the water storage changes within the Saq aquifer.

The comparison was first done at a monthly scale by comparing the water storage change coefficients for three cases: 1) a summer month against a winter month during the same year, 2) a summer month against the same 

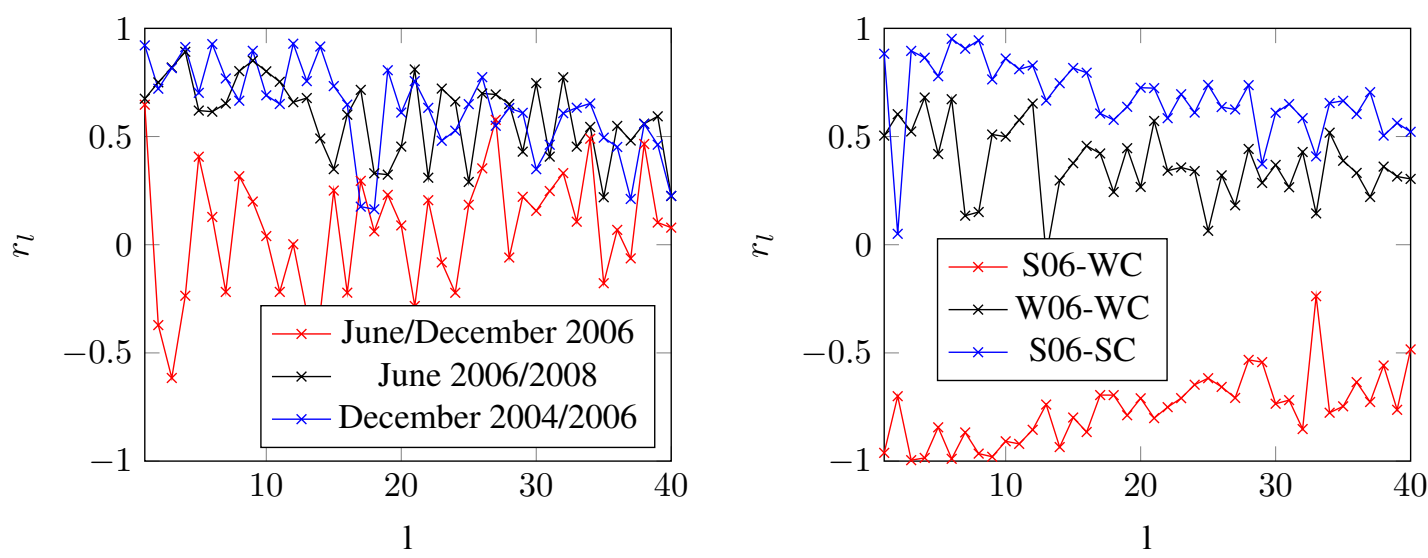

Figure 1. GRACE water storage change degree correlations between winter and summer months. Left: Monthly scale comparison. Right: summer-climatology (SC) and winter-climatology (WC) comparisons.

calendar month in another year, and 3) a winter month against the same calendar month in another year. Next, we obtained two climatological averages based on summer and winter periods, and used this climatology to compare against June and December of 2006. Figure 1 shows both the monthly (left) and climatologybased (right) degree correlation curve. The correlation between summer and winter months is clearly lower than when comparing points within the same season, although the distinction is more marked when using the climatology averages.

\subsection{MULTI-YEAR WATER BALANCE DEGREE CORRELATION}

A set of degree correlation results evaluating the water balance over the study sites was also examined. The first degree correlation curves were obtained by comparing a summer/winter climatology (June-August and December-February) of GRACE water storage changes against a similar climatology of the subtracted remote sensing coefficients (P-E). We used three different evaporation products resulting in three curves of degree correlation: GLEAM (Miralles et al., 2011), available at a $0.25^{\circ}$ resolution, MOD16 (Mu et al., 2011) at $0.05^{\circ}$ resolution and CSIRO (Zhang et al. 2012 ) at $0.25^{\circ}$ resolution. For the Saq aquifer, we also used ALEXI (Anderson et al. 2011) at a $0.04^{\circ}$ resolution. The degree correlation curves are shown in Figure 2 for both the Saq aquifer (left) and the Murray-Darling Basin (right), for both summer (top) and winter (bottom) climatologies.

The correlation curves suggest an inconsistency between the variables, given that for most of the degrees, the correlation is poor (less than 0.5 ). We can also see that there is a higher level of uncertainty within the evaporation products in the Saq aquifer during the summer months (Figure 2). There is no clear pattern of relationship between degree correlation and degree, and there is no significant difference between summer and winter months regarding the level of agreement between GRACE and the remote sensing products. Finally, we calculated the degree correlation curve at a monthly scale for every point in time available for each evaporation product. The result is shown in Figure 3 . The top row corresponds to the Saq Aquifer, while the bottom row corresponds to the Murray-Darling Basin. We see that for most of the time, the correlation is close to zero with only a few of the lowest degrees being highly correlated. The correlations at any time are in fact no better than the correlation between a winter and summer month of GRACE coefficients as shown in Figure 1 
O. Lopez et al., Evaluation of multiple remote sensing evaporation products...
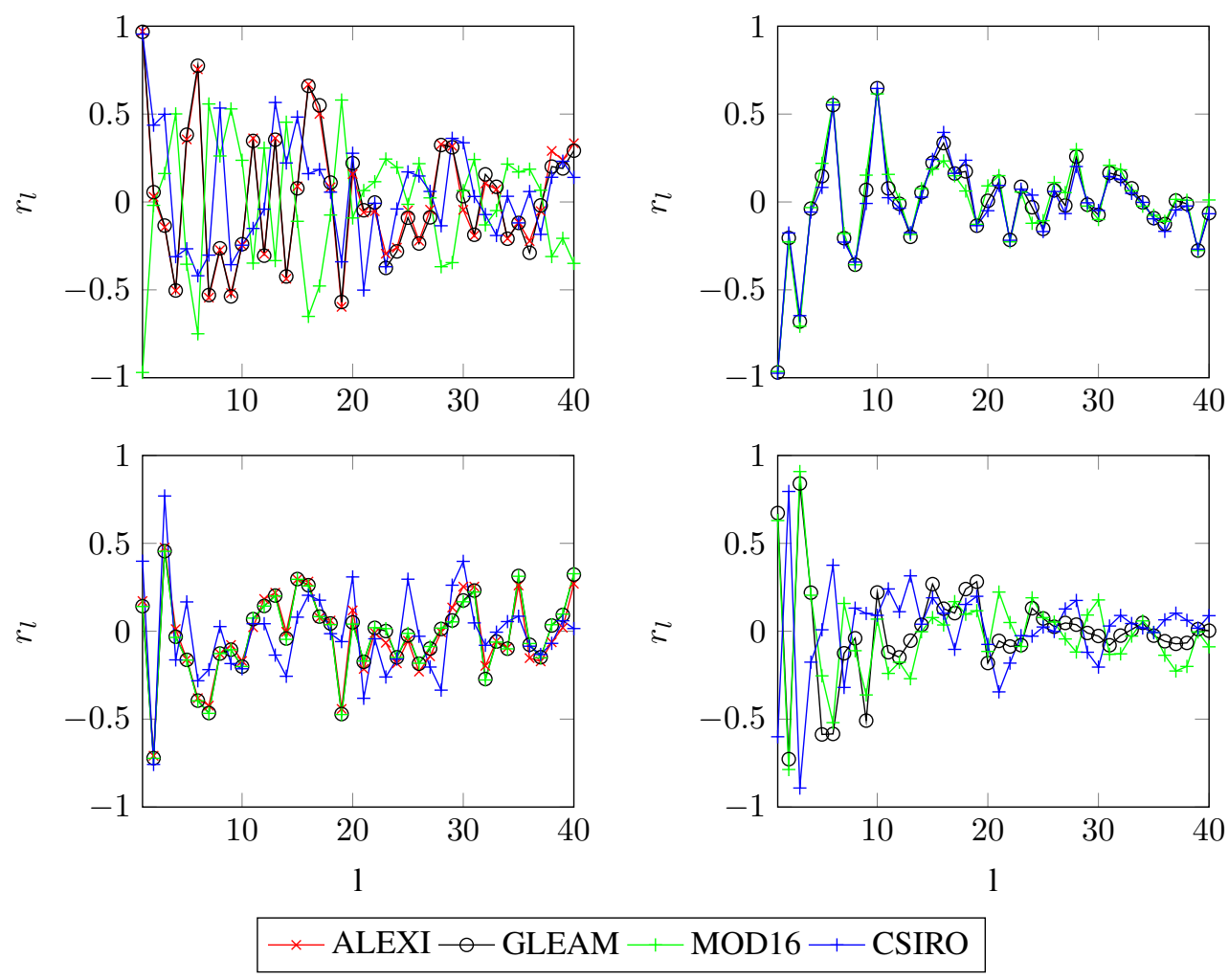

Figure 2. Comparison of summer (top) and winter (bottom)-based climatologies of GRACE water storage change coefficients and P-E coefficients within the Saq Aquifer (left) and Murray-Darling Basin (right)

\section{CONCLUSIONS}

This paper proposed to investigate the water balance of two dryland regions using water storage changes derived from GRACE satellites and precipitation and evaporation from remote sensing products. Processing GRACE data involves the use and filtering of spherical harmonic coefficients, which makes its use challenging when combined with other data sources. In this study, we transformed several remote sensing based evaporation products and one merged precipitation product into spherical harmonics to provide a spatial comparison of the water balance with GRACE. Our study showed inconsistencies in most of the spectral domain at multiple time scales, even in a study region where runoff, the only flux missing in our water balance, is negligible. In the Murray-Darling Basin the results were not significantly different. While other studies have already demonstrated the difficulty in closing the water balance using GRACE data and remote sensing data alone (e.g. Sheffield et al. 2009), our study reaffirms this knowledge through a different approach. This approach takes into account the reduction of the geophysical signal in GRACE due to the filtering process, which is otherwise accounted for by a scaling factor obtained with a hydrologic model (Long et al., 2015). Although our results suggest it is not possible to close the water balance by using satellite data alone, studies using multiple sources of information through integrative approaches provide an alternative approach to advance this task (Aires, 2014, Pan et al., 2012). Furthermore, the contribution of human-related activities such as intensive agriculture and water management need to be included in these efforts, particularly as large scale evaporation approaches are known to have difficulty in resolving such small activities.

\section{ACKNOWLEDGEMENT}

Research reported in this publication was supported by the King Abdullah University of Science and Technology (KAUST). 
O. Lopez et al., Evaluation of multiple remote sensing evaporation products...
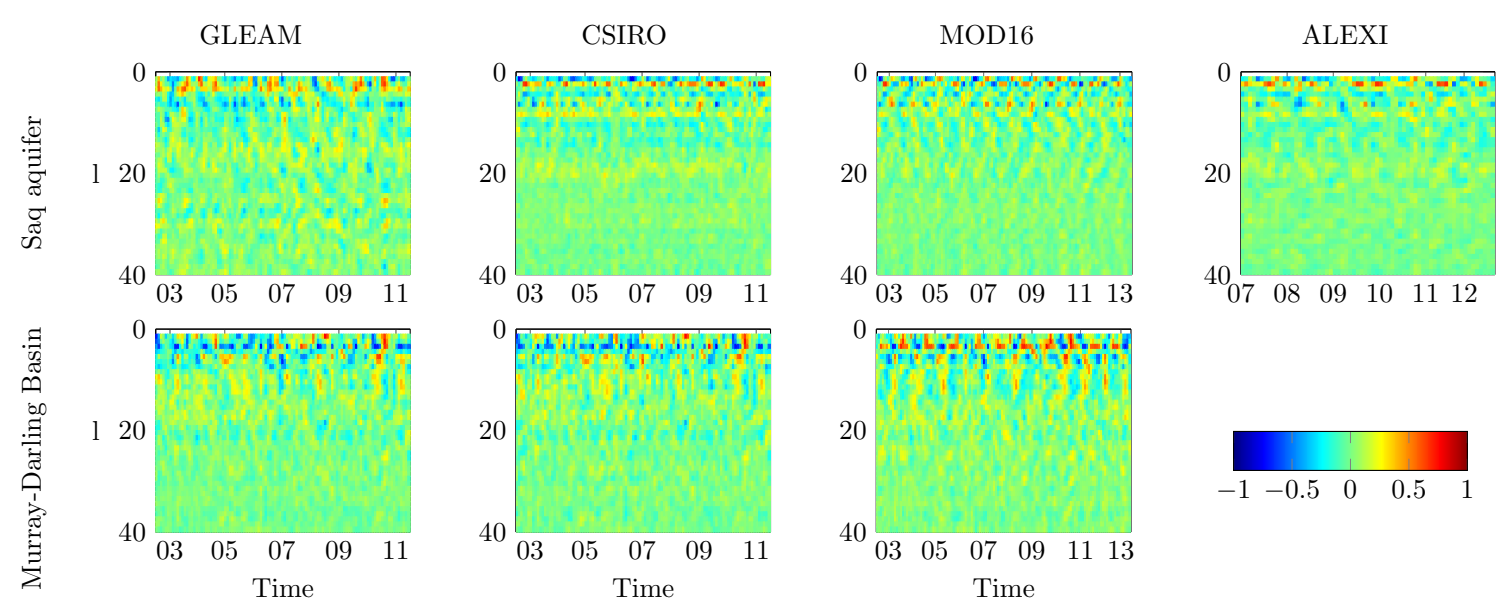

Figure 3. Degree correlation matrix comparing GRACE and P-ET using different evaporation products in the Saq aquifer (top) and Murray-Darling basin (bottom)

\section{REFERENCES}

Aires, F. (2014, Aug). Combining datasets of satellite-retrieved products. part i: Methodology and water budget closure. Journal of Hydrometeorology 15(4), 1677-1691.

Anderson, M. C., W. P. Kustas, J. M. Norman, C. R. Hain, J. R. Mecikalski, L. Schultz, M. P. González-Dugo, C. Cammalleri, G. D'Urso, A. Pimstein, and F. Gao (2011). Mapping daily evapotranspiration at field to continental scales using geostationary and polar orbiting satellite imagery. Hydrology and Earth System Sciences 15(1), 223-239.

El Kenawy, A. M. and M. F. McCabe (2015). A multi-decadal assessment of the performance of gauge- and model-based rainfall products over Saudi Arabia: climatology, anomalies and trends. International Journal of Climatology.

Ershadi, A., M. McCabe, J. Evans, N. Chaney, and E. Wood (2014). Multi-site evaluation of terrestrial evaporation models using FLUXNET data. Agricultural and Forest Meteorology 187(0), 46 - 61.

Evans, J. P. and M. F. McCabe (2010). Regional climate simulation over Australia's Murray-Darling basin: A multitemporal assessment. Journal of Geophysical Research: Atmospheres 115(D14).

Houborg, R., M. Rodell, B. Li, R. Reichle, and B. F. Zaitchik (2012). Drought indicators based on modelassimilated Gravity Recovery and Climate Experiment (GRACE) terrestrial water storage observations. Water Resources Research 48(7). W07525.

Jimenez, C., C. Prigent, B. Mueller, S. I. Seneviratne, M. F. McCabe, E. F. Wood, W. B. Rossow, G. Balsamo, A. K. Betts, P. A. Dirmeyer, J. B. Fisher, M. Jung, M. Kanamitsu, R. H. Reichle, M. Reichstein, M. Rodell, J. Sheffield, K. Tu, and K. Wang (2011). Global intercomparison of 12 land surface heat flux estimates. Journal of Geophysical Research: Atmospheres 116(D2).

Kummerow, C., J. Simpson, O. Thiele, W. Barnes, A. T. C. Chang, E. Stocker, R. F. Adler, A. Hou, R. Kakar, F. Wentz, P. Ashcroft, T. Kozu, Y. Hong, K. Okamoto, T. Iguchi, H. Kuroiwa, E. Im, Z. Haddad, G. Huffman, B. Ferrier, W. S. Olson, E. Zipser, E. A. Smith, T. T. Wilheit, G. North, T. Krishnamurti, and K. Nakamura (2000, Dec). The status of the Tropical Rainfall Measuring Mission (TRMM) after two years in orbit. Journal of Applied Meteorology 39(12), 1965-1982.

Landerer, F. W. and S. C. Swenson (2012). Accuracy of scaled GRACE terrestrial water storage estimates. Water Resources Research 48(4).

Liu, Y. Y., R. A. M. de Jeu, M. F. McCabe, J. P. Evans, and A. I. J. M. van Dijk (2011). Global long-term passive microwave satellite-based retrievals of vegetation optical depth. Geophysical Research Letters 38(18). L18402. 
O. Lopez et al., Evaluation of multiple remote sensing evaporation products...

Long, D., L. Longuevergne, and B. R. Scanlon (2015). Global analysis of approaches for deriving total water storage changes from grace satellites. Water Resources Research.

McCabe, M., E. Wood, R. Wjcik, M. Pan, J. Sheffield, H. Gao, and H. Su (2008). Hydrological consistency using multi-sensor remote sensing data for water and energy cycle studies. Remote Sensing of Environment 112(2), 430 - 444. Soil Moisture Experiments 2004 (SMEX04) Special Issue.

McCabe, M. F., A. Ershadi, C. Jimenez, D. G. Miralles, D. Michel, and E. F. Wood (2015). The GEWEX LandFlux project: evaluation of model evaporation using tower-based and globally gridded forcing data. Journal of Geophysical Research. In review.

McCabe, M. F., E. F. Wood, and H. Gao (2005). Initial soil moisture retrievals from AMSR-E: Multiscale comparison using in situ data and rainfall patterns over Iowa. Geophysical Research Letters 32(6). L06403.

Miralles, D., C. Jimenez, M. Jung, D. Michel, A. Ershadi, M. McCabe, M. Hirshi, A. Dolman, J. Fisher, B. Martens, Q. Mu, S. Seneviratne, E. Weber, U. Wood, and D. Fernandez-Prieto (2015). The WACMOSET project - part 2: Evaluation of global land evaporation data sets. Hydrology and Earth System Sciences Discussions. In review.

Miralles, D. G., T. R. H. Holmes, R. A. M. De Jeu, J. H. Gash, A. G. C. A. Meesters, and A. J. Dolman (2011). Global land-surface evaporation estimated from satellite-based observations. Hydrology and Earth System Sciences 15(2), 453-469.

Mu, Q., M. Zhao, and S. W. Running (2011). Improvements to a MODIS global terrestrial evapotranspiration algorithm. Remote Sensing of Environment 115(8), 1781 - 1800.

Mueller, B., M. Hirschi, C. Jimenez, P. Ciais, P. A. Dirmeyer, A. J. Dolman, J. B. Fisher, M. Jung, F. Ludwig, F. Maignan, D. Miralles, M. F. McCabe, M. Reichstein, J. Sheffield, K. C. Wang, E. F. Wood, Y. Zhang, and S. I. Seneviratne (2013). Benchmark products for land evapotranspiration: Landflux-eval multi-dataset synthesis. Hydrology and Earth System Sciences Discussions 10(1), 769-805.

Mueller, B., S. I. Seneviratne, C. Jimenez, T. Corti, M. Hirschi, G. Balsamo, P. Ciais, P. Dirmeyer, J. B. Fisher, Z. Guo, M. Jung, F. Maignan, M. F. McCabe, R. Reichle, M. Reichstein, M. Rodell, J. Sheffield, A. J. Teuling, K. Wang, E. F. Wood, and Y. Zhang (2011). Evaluation of global observations-based evapotranspiration datasets and ipcc ar4 simulations. Geophysical Research Letters 38(6).

Pan, M., A. K. Sahoo, T. J. Troy, R. K. Vinukollu, J. Sheffield, and E. F. Wood (2012, May). Multisource estimation of long-term terrestrial water budget for major global river basins. Journal of Climate 25(9), 3191-3206.

Sahoo, A. K., M. Pan, T. J. Troy, R. K. Vinukollu, J. Sheffield, and E. F. Wood (2011). Reconciling the global terrestrial water budget using satellite remote sensing. Remote Sensing of Environment 115(8), 1850 - 1865.

Sheffield, J., C. R. Ferguson, T. J. Troy, E. F. Wood, and M. F. McCabe (2009). Closing the terrestrial water budget from satellite remote sensing. Geophysical Research Letters 36(7).

Swenson, S. (2010, Apr). Assessing high-latitude winter precipitation from global precipitation analyses using GRACE. Journal of Hydrometeorology 11(2), 405-420.

Swenson, S. and J. Wahr (2006). Post-processing removal of correlated errors in GRACE data. Geophysical Research Letters 33, L08402.

Tapley, B., S. Bettadpur, J. C. Reis, P. F. Thompson, and M. M. Watkins (2004). GRACE measurements of mass variability in the earth system. Science 305, 503-505.

Wang, H., P. Wu, and Z. Wang (2006). An approach for spherical harmonic analysis of non-smooth data. Computers \& Geosciences 32(10), 1654 - 1668.

Wang, L., P. D’Odorico, J. P. Evans, D. J. Eldridge, M. F. McCabe, K. K. Caylor, and E. G. King (2012). Dryland ecohydrology and climate change: critical issues and technical advances. Hydrology and Earth System Sciences 16(8), 2585-2603.

Zhang, Y., R. Leuning, F. H. S. Chiew, E. Wang, L. Zhang, C. Liu, F. Sun, M. C. Peel, Y. Shen, and M. Jung (2012, Feb). Decadal trends in evaporation from global energy and water balances. Journal of Hydrometeorology 13(1), 379-391. 